\title{
Factual Survey of Education Using ICT Including E-learning in Japanese Physical Therapy Schools
}

\author{
MUTSUMI ONUKI ${ }^{1}$, HITOSHI MARUYAMA ${ }^{2)}$ \\ ${ }^{1)}$ Department of Physical Therapy, Chiba-kashiwa Rehabilitation College: 2673-1 Ohi, \\ Kashiwa City, Chiba 277-0902, Japan. TEL +81 4-7190-3000 \\ ${ }^{2)}$ Department of Physical Therapy, Faculty of Health Science, International University of \\ Health and Welfare
}

\begin{abstract}
Purpose] A questionnaire survey on e-learning in Japanese physical therapy schools was conducted in order to examine the efficiency and potential of the ICT-supported education by comparing the results with general Japanese higher education institutions. [Subjects and Methods] The questionnaire prepared by NIME in 2006 for higher education institutions was revised, and posted to 228 physical therapy schools in Japan (69 universities and 159 technical schools). [Results] Of all the questionnaires, 53.6\% (37/ $69)$ and $42.8 \%$ (68/159) were returned from the universities and technical schools, respectively. Many items in the questionnaire showed similar tendencies to the results of the NIME's survey. However, the "ascertainment of the learning effect of e-learning" showed a different tendency from general Japanese higher education institutions $(\mathrm{p}=0.000)$. [Conclusion] Physical therapy schools less frequently ascertain the learning effect of e-learning than general Japanese higher education institutions. The fact suggests that e-learning may not have been adapted by physical therapy education due to factors deemed unsuitable for e-learning such as the school capacity issues and technique-centered education.
\end{abstract}

Key words: E-learning, ICT, Factual survey

(This article was submitted Jul. 18, 2008, and was accepted Sep. 22, 2008)

\section{INTRODUCTION}

Recently, in higher education it has become wellknown that the use of e-learning can increase the efficiency/potential of teaching. This is true also for medical education, but in terms of e-learning used in higher education, Japan is reportedly far behind other countries such as European countries, the US, and Korea ${ }^{1)}$.

In fact, the National Institute of Multimedia Education (NIME) has already published reports on the present situation of e-learning in Japanese higher education institutions ${ }^{2}$, however no report is available on the present situation of e-learning in medical education, especially in Japanese physical therapy (PT) education.

The purposes of this research were to investigate the present situation of information communication technology (ICT)-supported education such as elearning in Japanese PT schools, and to perform a comparative study to examine the difference in elearning between universities and technical schools.

\section{SUBJECTS AND METHODS}

A questionnaire asking about the use of ICT such as e-learning in each school was sent to $228 \mathrm{PT}$ schools (69 universities and 159 technical schools).

The authors revised the questionnaire for higher education institutions made by NIME in $2006^{3)}$ and 
added 4 original question items to finally include 22 items (Table 1).

This survey was conducted in December, 2007 for 1 month using the mailing method, and the questionnaire explained ethical matters, including that it was an anonymous survey and that we would be very careful handling the obtained information.

Statistical analysis was performed using a chisquare test with a significance level of $5 \%$. The statistical software Dr. SPSSII was used.

\section{RESULTS}

Of all the questionnaires, 53.6\% (37/69) and $42.8 \%(68 / 159)$ were returned from universities and technical schools, respectively. Table 1 shows the results of the survey.

The comparison between the results of NIME and PT schools showed significant differences in questions 6, 7, 10, 14 and $17(\mathrm{Q} 6, \mathrm{p}=0.037$; Q7, $\mathrm{p}$ $=0.045 ; \mathrm{Q} 10, \mathrm{p}=0.011 ; \mathrm{Q} 14, \mathrm{p}=0.000 ; \mathrm{Q} 17, \mathrm{p}=$ 0.000 ).

The comparison between universities and technical schools in the survey for PT schools showed significant differences in questions 6,7 and $14(\mathrm{Q} 6, \mathrm{p}=0.008 ; \mathrm{Q} 7, \mathrm{p}=0.000 ; \mathrm{Q} 14, \mathrm{p}=0.000)$.

Question 17 showed a very significant difference between the results of NIME and PT schools, but not between the two types of PT school, universities and technical schools.

For our original questions 3,4 and 5 asked only to PT schools, the following 3 results were obtained.

1. Most universities have ICT facilities, but $20 \%$ of technical schools do not.

2. As much as $70 \%$ of all technical schools answered the rate of ICT use as "zero" (the rate was $40 \%$ in universities).

3. The question asked which process in the taxonomy is necessary for e-learning, based on the Benjamin Bloom's classification ${ }^{4)}$. The most frequent answer was "only cognitive domain" in both universities and technical schools. As a whole, similar tendencies were observed in the both groups.

\section{DISCUSSION}

The comparison between the results of NIME and PT schools showed similar tendencies, which suggests that the present situation of e-learning in Japanese PT schools may be similar to that in general Japanese higher education institutions in 2006.

Since questions 6 and 7 were more ambiguous than other questions, and allowed multiple answers, they may have provided biased results.

Question 14 showed a very significant difference in the chi-square tests, which might have occurred because PT schools frequently answered: "others".

On the other hand, question 17 on "ascertainment of the learning effect of e-learning" showed an obvious difference between the results of NIME and PT schools. Based on the absence of correlation and the highly significant difference observed in the chi-square tests, the results of this question may have suggested our (PT schools') specificity. The results clearly indicate the fact that general Japanese higher education institutions often perform question surveys and examinations to ascertain the learning effect of e-learning (55\% and $48 \%$, respectively), while $40 \%$ of Japanese PT schools do nothing in particular.

This may be because e-learning has not been adapted in PT education due to factors which deem it unsuitable for e-learning such as the school capacity issue and technique-centered education.

For the comparison between universities and technical schools, the results of our original questions suggest the following. Use of ICT may increase the cost and burden of maintenance in universities, and need more work from each teacher in technical schools, thus the scale and economic context of each educational institution may influence the use of ICT. Universities have advantages over technical schools, because universities can acquire budgets for e-learning more easily under the Ministry of Education, Culture, Sports, Science and Technology's "Contemporary Education Needs Initiative Support Program" (Contemporary Good Practice) which was initiated in 2004 to revitalize higher education ${ }^{5)}$.

Question 17 showed the specificity of PT schools in comparison with the results of NIME, but no difference was observed between universities and technical schools. Therefore, it seems a unique characteristic of PT schools.

Many items of our questionnaire showed similar tendencies to NIME, which revealed that the present situation of e-learning in Japanese PT schools including technical schools as well as universities is similar to that of general Japanese higher education institutions. However, PT schools 
Table 1. A questionnaire about education: applied ICT such as the E-learning in...?

Q1 Which is the kind of your educational institution?

1. National university

2. Public university

3. Private university

4. Junior college

5. College of technology

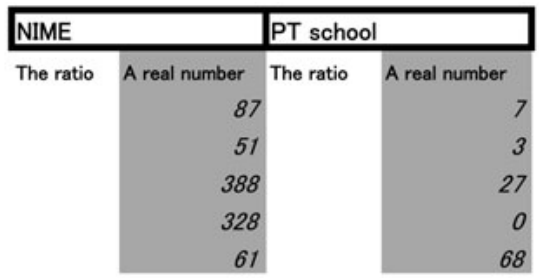

Q2 Is one grade of capacity of the subject several people?

(Abbreviation)

Q3 Are there ICT facilities where a student can use the Internet in class ?

1. I have exclusive facilities.

2. I have facilities for common use.

3. The ICT facilities such as PC rooms do not exist.

Q4 What is the ratio of e-learning in class ?(It excludes a basic subject)

1. $\mathrm{O} \%$

2. $\sim 20 \%$

3. $20 \sim 40 \%$

4. $40 \sim 60 \%$

5. $60 \sim 80 \%$

6. $80 \sim 100 \%$

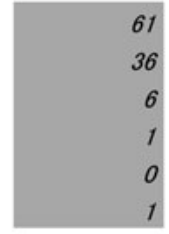

Q5 In PT-education, how necessary is e-learning?

1. Not necessary at all

2. I think that it is necessary, but it is not necessary to use it in education of PT(If anything, it is OJT)

3. Only the part of the cognitive domain is necessary

4. It is necessary in the part of the recognition domain / and emotion and will domain

5. It is necessary in the cognitive domain / emotion and will domain / mind movement domain

6. No answer

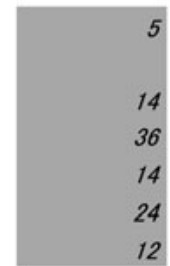

Q6 Please answer about current action for ICT practical use education.(multiple responses)

1. Improvements to quality of educational contents \& courses using ICT

2. Enrichment of educational contents \& courses using ICT

3. Combining face-to-face tuition \& e-learning (through blended learning)

4. Fostering personnel for education using ICT

5. Faculty development for education using ICT

6. Promotion through university-wide activities

7. Promotion of collaboration with other departments and faculties

8. Promotion of collaboration with other universities in Japan

9. Promotion of collaboration with overseas universities

10. Other

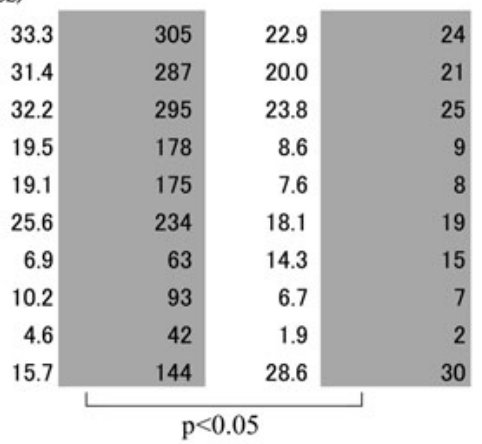

Q7 Please answer about future action policy for ICT practical use education.(multiple responses)

1. Improvements to quality of educational contents \& courses using ICT

2. Enrichment of educational contents \& courses using ICT

3. Combining face-to-face tuition \& e-learning (through blended learning)

4. Fostering personnel for education using ICT

5. Faculty development for education using ICT

6. Promotion through university-wide activities

7. Promotion of collaboration with other departments and faculties

8. Promotion of collaboration with other universities in Japan

9. Promotion of collaboration with overseas universities

10. Other

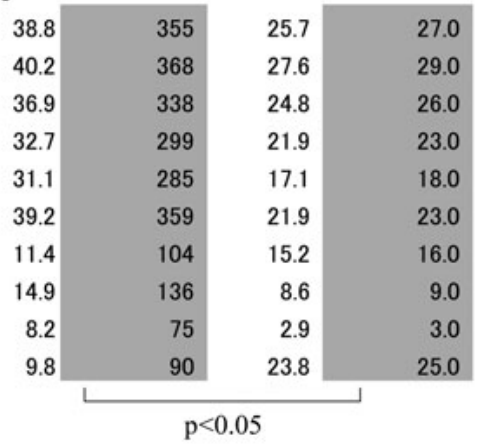


Q8 Have you introduced ICT practical use education?

1. Have introduced

2. Have not introduced

3. No answer
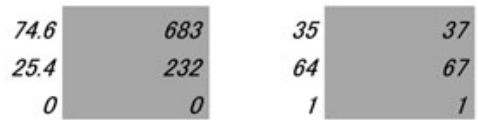

Q9 What kind of organization is involved in promoting ICT practical use education?(multiple responses)

1. Cross-university committee or working group set up

2. Internal organization (Information education center, faculty etc.)

3. Individual teachers, no organizational measures taken

4. Consortium with other Japanese university

5. Consortium with overseas university

6. Other

Q10 What is the situation of using ICT program in your school? (multiple responses)

1. Education of faculty and department at universities, junior colleges \& colleges of technology

2. Remedial education (supplementary scholastic education)

3. Extramural lectures

4. Life learning, adult education

5. For national examination \& qualification accreditation

6. Other
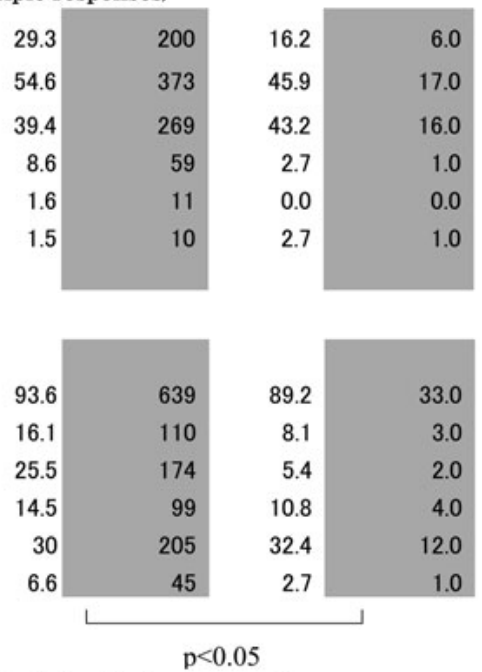

Q11 Please answer about the purpose of introduction of ICT inflection education of your school. (multiple responses)
1. To provide students with effective education
2. To adapt to various learning formats
3. To provide efficient education
4. To provide high quality education
5. To rationalize education and administration
6. To attract new students
7. To reduce costs
8. Other

\begin{tabular}{|r|r|r|r|}
81.1 & 554 & 89.2 & 33.0 \\
59 & 403 & 67.6 & 25.0 \\
60.6 & 414 & 73.0 & 27.0 \\
\hline 47.7 & 326 & 43.2 & 16.0 \\
18.7 & 128 & 16.2 & 6.0 \\
5.3 & 36 & 2.7 & 1.0 \\
3.8 & 26 & 0.0 & 0.0 \\
2.8 & 19 & 5.4 & 2.0 \\
\hline
\end{tabular}

Q12 What are the merits of having introduced ICT practical use education ? (multiple responses)

1. Enabled students to learn anytime, anywhere

2. Enabled more effective education (e.g. contribution to better academic ability)

3. Enabled teaching appropriate to students' needs

4. Enabled individual teaching through two-way communication

5. Enabled efficient education (e.g. by reducing manpower)

6. Easier to reduce costs than face-to-face tuition

7. Enabled educational activities across a wide geographical area

8. Students' self-learning has been vitalized

9. Other

Q13 What are the problems of carrying out ICT education? (multiple responses)

1. Dean and senior staff do not adequately appreciate education using ICT

2. Unable to gain a consensus within the school about support for education using ICT

3. Inadequate understanding of effects of education usinig ICT on the part of teaching staff

4. Lack of teachers' skills in education using ICT

5. Lack of students' skills in education using ICT

6. Lack of knowledge about development of e-learning lecture and teaching systems

7. Lack of knowledge about handling copyrights

8. Unable to obtain a budget for introduction of education using ICT

9. Infrastructure for introduction of education using ICT not in place
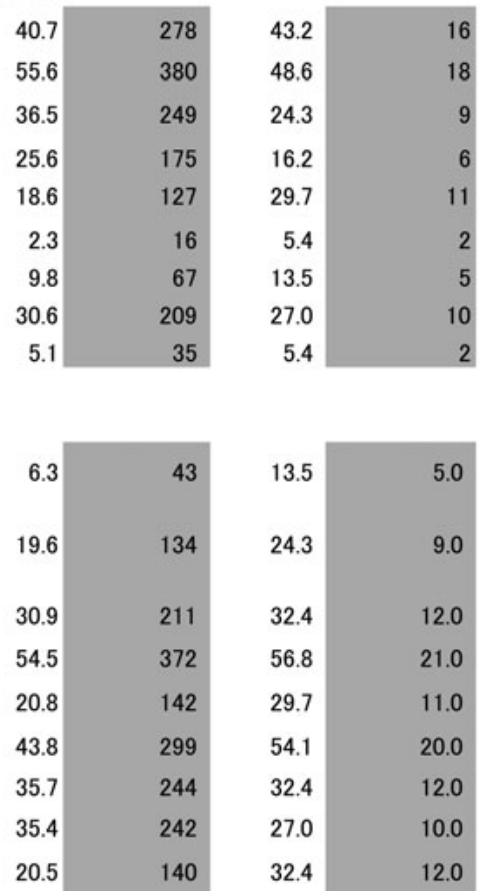
10. No platform that meets the achievements of the organization

11. Lack of learning support system for students

12. Lack of personnel to create and maintain system and contents

13. Preparation of an organized in-school cooperative system

14. No incentives for teaching regarding education using ICT

15. Other
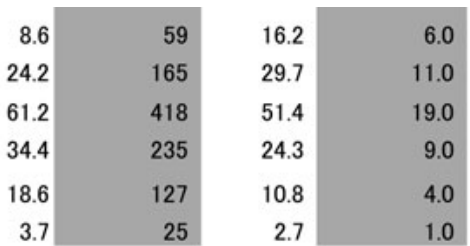

Q14 What are the demerits of having introduced ICT practical use education? (multiple responses)

1. Teaching staff have to spend more time creating contents and preparing lessons

2. More expensive than face-to-face tuition

3. Learning effects ware inferior to face-to-facetuition

4. Difficult to sustain students' will to learn

5. Lesser communication with students suffers

6. Burden of maintaining and managing system

7. Other

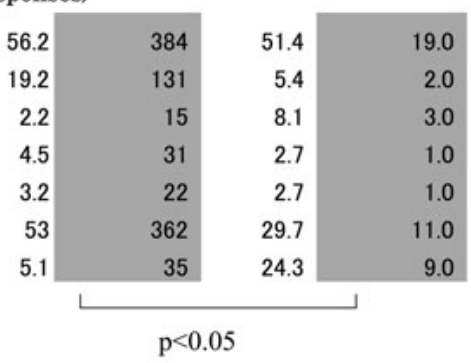

Q15 Who is involved in deciding subject content for education using ICT practical education ? (multiple responses)

1. Cross-university organization (center or committee or working group)

2. Individual teachers, no organizational measures taken

3. University consortium

4. Outsourced

5. Other

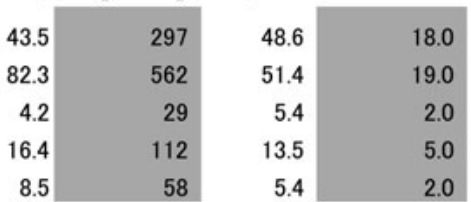

Q16 Please answer about facilities and methods used by institutions introducing education using ICT.(multiple responses)

1. Equipped with large screens or multiple displays enabling education using ICT

2. Able to upload teaching materials to the internet, student can look at them on their computers.

3. Discussions between students are held on electronic bulletin boards.

4. Short tests are conducted over PCs and mobile terminals.

5. Students can send reports via PCs and mobile terminals.

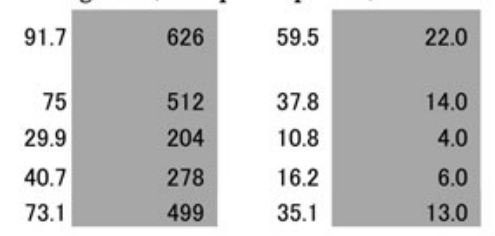

Q17 How do you ascertaining academic effect of education using ICT? (multiple responses)

1. Conducting questionnaires

2. Conducting tests

3. Ascertaining from the number of credits obtained.

4. No particular methods used

5. Other

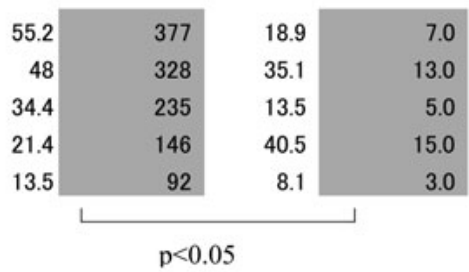

Q18 Please answer about the examinations using ICT.

1. Considering introduction.

2 . Introduction planned.

3. Neither considered nor planned.

4. Introduced in the past, but ceased introduction.

5. No answer
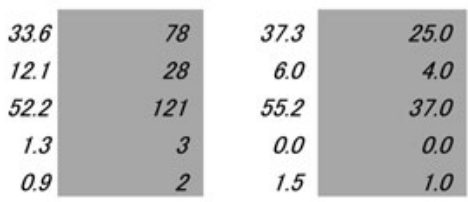

Q19 What kind of thing is the planned organization form to introduce? (multiple responses)

1. Through cross-university effort.

2. Through an internal organization (information education center, faculty etc.)

3. Through establishment of a new organization.

4. Through a consortium with other Japanese university.

5. Through a consortium with overseas university.

6. Through individual teachers, no organizational measures taken.

7. Other

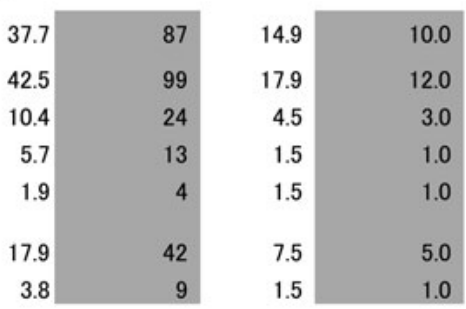


Q20 What are the problems of introducing ICT practical use education? (multiple responses)

1. Dean and senior staff do not adequately appreciate education using ICT

2. Unable to gain a consensus within the school about support for education using ICT

3. Inadequate understanding of effects of education usinig ICT on the part of teaching staff

4. Lack of teachers' skills in education using ICT

5. Lack of students' skills in education using ICT

6. Lack of knowledge about development of e-learning lecture and teaching systems

7. Lack of knowledge about handling copyrights

8. Unable to obtain a budget for introduction of education using ICT

9. Infrastructure for introduction of education using ICT not in place

10. No platform that meets the achievements of the organization

11. Lack of learning support system for students

12. Lack of personnel to create and maintain system and contents

13. Preparation of an organized in-school cooperative system

14. No incentives for teaching regarding education using ICT

15. Other
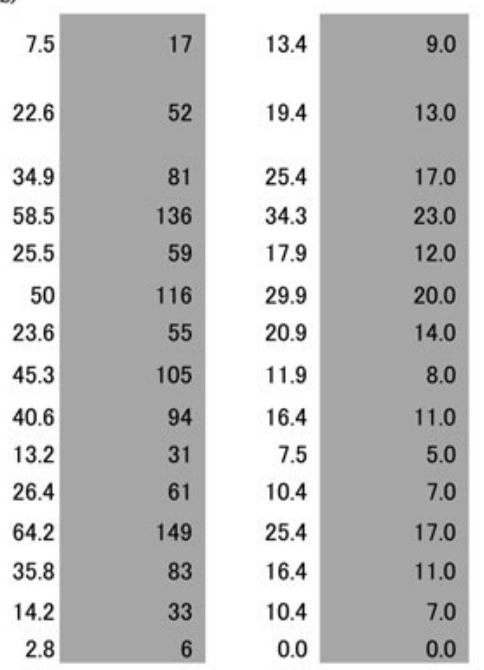

Q21 Please give the reasons why e-learning has not been introduced.(multiple responses)

1. Due to lack of interest in e-learning within the university.

2. Due to lack of know-how on e-learning adaption.

3. Due to lack of developed infrastructure in the university.

4. Due to lower instructional impact than face-to-face tuition.

5. Due to a lack of effects that counterbalance costs.

6. Due to insufficlent funding for introduction.

7. Due to a preponderance of skills courses and other such courses not suited to $e^{-}$ learning.

8. Other
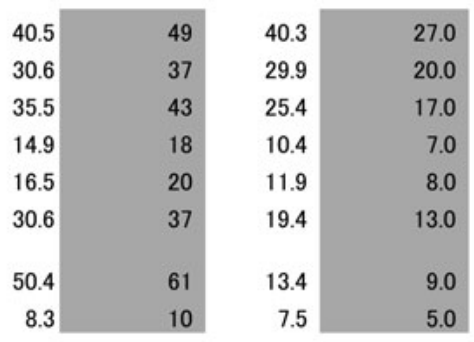

Q22 Please answer when ICT practical use education was introduced and terminated.

(Abbreviation)

showed different tendencies from those of general Japanese higher education institutions for some items (e.g. ascertainment of the learning effect of elearning). Different types of PT schools, i.e. universities and technical schools showed different tendencies in some items (e.g. approach to ICT use in education and disadvantages of the introduced ICT).

Toward an ICT-supported PT education including e-learning, it will be necessary to remove the specificity of PT schools observed in question 17 and to decrease the disadvantages which are much more frequently seen in technical schools.

\section{ACKNOWLEDGMENT}

We sincerely thank the teachers in PT schools who responded to this questionnaire survey.

\section{REFERENCES}

1) Onuki M, Maruyama H: Current state and the future of e-learning in physical therapy education, Rigakuryoho Kagaku, 2007, 22: 547-551 (in Japanese).

2) NIME (National Institute of Multimedia Education): Collection and Analysis of the Information on Education. Using ICT. http://www.nime.ac.jp/activity/ 033.html (Accessed May 5, 2008)

3) NIME (National Institute of Multimedia Education): Report on Education Using ICT Including e-Learning, 2006. http:/www.nime.ac.jp/reports/001/2006/main/ eLearning-jp.pdf (Accessed May 5, 2008)

4) Kern DE, Thomas PA, Howard DM, et al. Translated by Shunzou Koizumi: Curriculum Development for Medical Education: A Six-Step Approach. Tokyo: Shinoharashinsha, Inc, 2003, pp36-42 (in Japanese).

5) E-Learning White Paper 2006/2007. Tokyo: Tokyo Denki University Press, 2006, pp134-135 (in Japanese). 